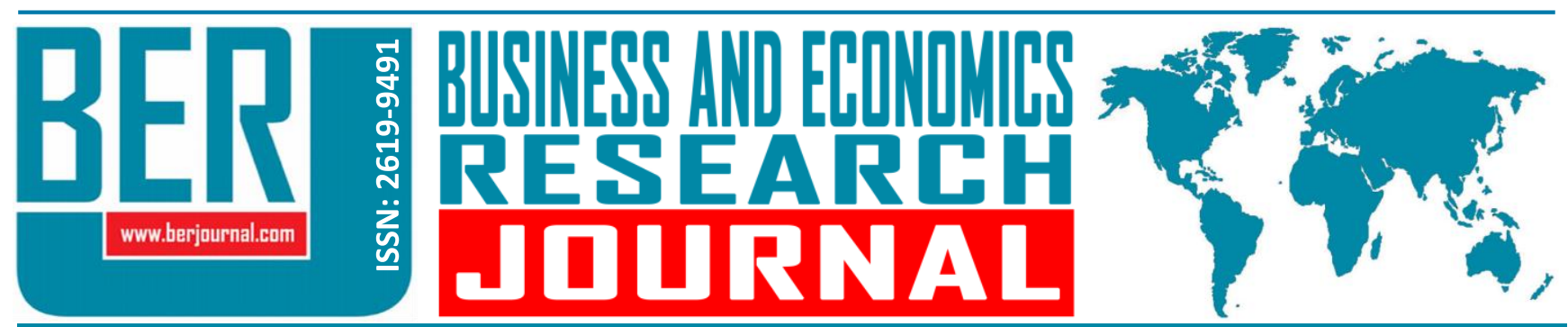

Business and Economics Research Journal Vol. 9, No. 3, 2018, pp. 531-542 doi: 10.20409/berj.2018.121

\section{Gri Tahmin ve Markov Modeli ile Türk İmalat Sanayinin Satış Gelirinin Öngörüsü}

\author{
Selahattin Kaynak ${ }^{\mathrm{a}}$, Mirac Eren ${ }^{\mathrm{b}}$
}

Öz: Türk Imalat sanayi, serbest piyasa ekonomisinin benimsenmesiyle birlikte önemi giderek artmış; istihdam, üretim ve ihracat açısından Türk ekonomisinin itici gücü haline gelmiştir. Sermaye sahipliği açısından Türk imalat sanayinde; kamu, özel ve yabancı sermayeli türünde farklı statüdeki firmalar faaliyet göstermektedir. Türk imalat sanayinde sermaye sahipliği gelirleri trendlerini Gri (Grey) ve Markov modeli ile tahmin etmek, bu çalışmanın amacını teşkil etmektedir. Firmaların toplam satış geliri tahmininde gri modeli, eğilimleri için de kuadratik programlama modeline dayalı yeni Markov yaklaşımı önerilmiştir. Bu modeller, firmaların 2004-2014 dönemine ait toplam satışlarını öngörmek ve 2017-2022 döneminin trendleri tahmin etmek için kullanılmıştır. Araştırma kapsamında, Türkiye'nin en büyük 500 sanayi kuruluşu arasında yer alan ve aynı zamanda imalat sanayinde faaliyet gösteren firmaların satış gelirleri analiz edilmiştir. Analiz edilen veri seti 1993-2014 dönemini kapsamaktadır. Yapılan analizler sonucunda, Türk imalat sanayinde kamu sermayesinin ağırlı̆ıı giderek azaldığı ve özel sermaye türüne yüksek düzeyde geçişin olduğu tespit edilmiştir.

\section{Forecasting Sales Revenues of Turkish Manufacturing Industry by Grey Forecasting and Markov Model}

\begin{abstract}
Turkish manufacturing industry has been increasingly important with the adoption of free market economy. It has become the driving force of the Turkish economy in terms of employment, production and exports. In terms of capital ownership, in Turkish manufacturing industry; public, private and foreign capital type companies operate in different status. The aim of this study is to predict the sales income trends of the public, private and foreign capital types operating in different positions in terms of capital ownership in the Turkish manufacturing industry through the Grey and Markov model. The grey model for estimating the total sales revenue of the firms, and the new Markov approach based on the quadratic programming model for their trends have been proposed. These models were used to forecast the total sales of firms for the period 2004-2014 and to estimate the trends of 2017-2022 period. In the scope of the research, the sales revenues of Turkey's largest 500 industrial firms, operating in the manufacturing industry were analyzed. The analyzed dataset covers the period 1993-2014. As a result of the analyzes, it has been found that in the Turkish manufacturing industry, the weight of public capital is gradually decreasing and that the private capital has a high level of penetration.
\end{abstract} açısından farklı statüde faaliyet gösteren kamu, özel ve yabancı sermaye türlerinin satış

Anahtar Sözcükler: Imalat Sanayi, Markov Modeli, Kuadratik Programlama, Gri Model

JEL: D29, D41, E23

$\begin{array}{ll}\text { Geliş } & : 23 \text { Mart } 2018 \\ \text { Düzeltme } & : 04 \text { Mayıs } 2018 \\ \text { Kabul } & : 24 \text { Mayıs } 2018 \\ \text { Tür } & : \text { Araştırma }\end{array}$

Keywords: Manufacturing Industry, Markov Model, Quadratic Programming, Grey Model

JEL: D29, D41, E23

$\begin{array}{ll}\text { Received } & : 23 \text { March } 2018 \\ \text { Revised } & : 04 \text { May } 2018 \\ \text { Accepted } & : 24 \text { May } 2018 \\ \text { Type } & : \text { Research }\end{array}$

(2018). Gri tahmin ve Markov modeli ile Türk imalat sanayinin satıs gelirinin öngörüsü. Business and Economics Research Journal, 9(3), 531-542.

The current issue and archive of this Journal is available at: www.berjournal.com

a Assoc. Prof., PhD., Ondokuz Mayıs University, Faculty of Economics and Administrative Sciences, Department of Economics, Samsun, Turkiye, selahattin.kaynak@omu.edu.tr (ORCID ID: 0000-0003-0082-5961)

b Asst. Prof., PhD., Ondokuz Mayıs University, Faculty of Economics and Administrative Sciences, Department of Economics, Samsun, Turkiye, mirac.eren@omu.edu.tr (ORCID ID: 0000-0002-5150-9144) 


\section{Giriş}

Ülkelerin ekonomik yapılarının tarım sektöründen sanayi sektörüne doğru kaymasıyla birlikte imalat sanayi; büyümenin, verimliliğin, ihracatın ve teknoloji transferinin en önemli unsuru haline gelmiştir. Gelişmiş ülkelerin ekonomilerinin ortak özelliklerinden birisi de güçlü bir imalat sanayine sahip olmalarıdır.

Gelişmiş ekonomilerde verimlilik artışı ve büyüme için yapılan Ar-Ge harcamalarının büyük bir kısmı imalat sanayi bünyesinde gerçekleşmektedir. Ayrıca kronik hale dönüşmüş birçok iktisadi sorunların çözümü, yüksek katma değerli bir imalat sanayi yapısına sahip olmakla mümkündür (ÖiK, 2014:144).

Türk imalat sanayi, serbest piyasa ekonomisinin kabul edilmesi ve ekonominin küreselleşmesiyle birlikte ekonomideki ağırlığı giderek artmış ve Türk ekonomisinin itici gücü haline gelmiştir. Tüik dış ticaret verilerine göre 2015 ve 2016 yıllarında Türkiye'deki toplam ihracatın \%93'ü imalat sanayi tarafından gerçekleşmiştir (Dış Ticaret İstatistikleri, Mayıs 2017).

Sermaye sahipliği açısından Türk imalat sanayinde faaliyet gösteren firmalar, kamu, özel ve yabancı sermaye statüsünde faaliyet göstermektedirler.

Gelişmekte olan ülkelerin çoğunda kamu sermayeli firmalar daha çok enerji, ulaşım, telekomünikasyon ve altyapı gibi alanlarda faaliyet göstermektedir (OECD, 2015:12). Ancak kamu sermayeli firmalar, verimlilik ve rekabet açısında özel sektörün gerisinde kaldığı gerekçesiyle sürekli eleştirilmiştir.

Türkiye Cumhuriyetinin ilk kuruluş yıllarında özel sektörün yetersiz oluşu ve bireysel girişim kültürünün yerleşmemiş olması, kamu sermayeli firmaların imalat sanayinde yer almasına neden olmuştur. Kamu sermayeli firmaların imalat sektöründeki payı 1950 sonrası dönemde tartışımasına rağmen, Türk ekonomisindeki ağırlığı 1980'li yıllara kadar devam etmiştir. 1980'den sonra özelleştirme çabaları, kamu sermayeli firmalarda verimlilik ve etkinliğin düşük olduğu düşüncesi sonucunda Türk ekonomisinde özel sektörün payı giderek artış göstermiştir (Albeni, 2005:127). Türkiye'de 1980 öncesi dönemine ilişkin yapılmış çalışmalarda kamu işletmelerinde verimliliğin özel sektöre nispetten daha yüksek olduğu tespit edilirken (Krueger ve Tuncer, 1982); 1980 sonrası dönemde ise özel sektörde verimliliğin daha yüksek olduğu tespit edilmiştir (Zaim ve Taşkın, 1997). Ayrıca reel ücret ve işgücü verimliliğinin kamu sermayeli firmalara nazaran özel sektörde daha yüksek olduğu ve işgücü verimliliği ile reel ücretler arasında yalnızca özel sektörde anlamlı bir ilişki olduğu tespit edilmiştir (Türedi ve Terzi, 2009:146). Türkiye'de birçok kamu sermayeli kuruluş beş yıllık kalkınma planları ile özelleştirme kapsamına alınarak 1987 yılından itibaren özel sektöre devredilmiştir.

Üretim faktörleri açısından zengin olan ülkelerde faktörlerin fiyatı düşük, az olan ülkelerde ise yüksektir. Bu durum ise yabancı sermaye yatırımlarının ortaya çıkmasına neden olmaktadır (Jenkins, 1987:18). İmalat sanayinde yabancı sermayeli firmaların varlığı ekonomik büyümeyi hızlandırmaktadır. Bunun yanısıra yabancı sermayeli firmalar gelişmekte olan ülke ekonomilerine üretim, istihdam, rekabet ortamının oluşması, eski teknoloji yerine yeni teknoloji transferi ve dış piyasalara açılma imkanı da sağlamaktadır.

Türkiye, 1980 'li yılardan sonra dışa açık iktisadi politikalar benimseyerek yabancı sermayenin girişini artırmayı hedeflemiştir (Berköz ve Türk, 2007:59). Türk imalat sanayi ve hizmetler sektörü, yabancı sermayenin en çok ilgi gösterdiği sektörlerdir. 2015 yılında Türk imalat sektöründe yabancı sermayenin en fazla yer aldığı sektörler sırasıyla rafine edilmiş petrol ürünleri, gıda, içecek ve tütün sektöründe iken; 2016 yılında bu üstünlük gıda, içecek, bilgisayar, elektronik ve optik ürünlerine geçmiştir. Sermaye büyüklüğü açısından Türkiye'ye en fazla yatırım yapan ülkeler Avrupa Birliğine üye ülkelerdir (TCMB Sektör Raporları, 2017).

Türk imalat sanayinde üretim faktörlerinin sahipliği (özellikle sermaye sahipliği) açısından hangi türdeki firmaların satış gelirinde ağılık teşkil ettiğinin/edeceğinin bilinmesi araştırmacılar, firma sahipleri ve kamu adına karar verme yetkisine sahip olanalar için önem arz etmektedir. Kamu, yabancı ve özel sermayeli firmaların toplam satış gelirleri paylarının tahmini ve öngörüsünü regresyon analizi, zaman serileri analizi, yapay sinir ağı, yarı parametrik, parametrik ve parametrik olmayan yöntemler gibi birçok model ile analiz etmek mümkündür. Ancak, Türk imalat sanayinde faaliyet gösteren firmaların satış gelirleri özelleştirme, ulusal ve uluslararası birleşmeler/devralmalar sonucunda özel, yabancı ve kamu sermayeli türler arasında bir 
dönüşüm ve geçiş yaşamıştır. Bu nedenle, farklı sermaye sahipliği türlerinin satış gelirleri paylarının geçişkenliklerine göre gelecekteki oranlarının belirlenmesi için Markov modeli yaklaşımı kullanıımıştır. Ayrıca, Türk imalat sanayinde faaliyet gösteren firmaların toplam satış gelirlerinin geleceğe yönelik tahmini için de literatürde bahsi geçen tekniklerin kullanılması çok sayıda gözlem, varsayım ve karmaşık girdi faktörü gerektirdiğinden çalışmada geleneksel tahmin modelleri yerine sınırlı veri seti ile tahmin olanağı sağlayan ve Gri sistem teorisinin bir dalı olan Gri Tahmin Modeli (GM) kullanılmıştır. Böylece farklı sermaye türlerinin geleceğe yönelik satış gelirleri ortaya çıkarıımıştır.

Gri sistem teorisinin bir dalı olan Gri Tahmin Modeli (GM) özelinde GM(1,1) modeli, Prof. Deng Julong tarafından önerilmiş ve Çin'in tahıl verimi tahmininde kullanılmıştır (Julong, 1983, 1985). Süregelen çalışmalarda modelin geniş bir uygulanabilirliğe sahip olduğunu kanıtlamıştır (Wu vd., 2015; Wang vd., 2016). 1906 yılında Andre Markov tarafından önerilmiş olan Markov zinciri doğal bilimler, mühendislik teknolojisi ve kamu hizmetlerinde yaygın olarak kullanılmıştır (Zhao vd., 2014; Shen vd., 2015; Casale, Sansottera ve Cremonesi, 2016; Liisberg vd., 2016). Son dönemlerde ise özellikle enerji alanında Gri model ve Markov karar zinciri modeli birlikte kullanılmaktadır. Enerji kaynaklarının zamanla dönüşüm ve geçişkenlik yapısından dolayı bu yapısal geçişi öngörmek için markov karar zincirini ve toplam enerji tüketimini tahmin etmek için de $\mathrm{GM}(1,1)$ modelini kullanan çalışmalar mevcuttur (Xie, Yuan ve Yang, 2015; Ren ve Gu, 2016)

Çalışma veri alt başlığında, Türk imalat sanayinde sermaye sahipliği açısından tasnif edilen kamu, özel ve yabancı sermayeli firmaların 1993-2014 yıllarındaki satış gelirleri toplamlarına göre her bir sermaye sahipliği türünün verilerine ilişkin oluşturulan bilgiler mevcuttur. Metodoloji başlığında kuadratik programlamaya dayalı Markov yaklaşımı ve gri tahmin prosedürünü açıklayan başılıklara yer verilmiştir. Bulgular başlığında Türk imalat sanayindeki her bir sermaye sahipliği türünün satış gelirleri paylarının geçişkenlik oranları ve tahmini verileri elde edilmiştir. Ayrıca, toplam satış gelirlerinin geleceğe yönelik tahmini verileri bulunmuştur. Sonuç ve Öneriler başlı̆ında ise sermaye sahipliği açısından hangi türün satış gelirinde ağırlık teşkil ettiğinin/edeceğine ilişkin araştırmacılar, firma sahipleri ve kamu adına politik karar alıcılara bir takım önerilerde bulunulmuştur.

\section{Veri}

Türk imalat sanayinde; kamu, özel ve yabancı sermayeli türünde farklı statüdeki firmalar faaliyet göstermektedirler. Çalışmada, Türkiye'nin en büyük 500 yabancı, özel ve kamu sermayeli firmaların satış gelirleri kullanılmıştır. 1993-2014 yılları arasındaki satış geliri İstanbul Sanayi Odasının her yıl hazırladığı "Türkiye'nin 500 büyük sanayi kuruluşu" çalışmalarından alınmıştır. Bu çalışmalarda sadece imalat, madencilik ve elektrik sektörlerinde faaliyet gösteren firmalar dikkate alınmaktadır. Hizmetler sektöründe faaliyet gösteren firmalar bu kapsama dahil edilmemektedir. Türk imalat sanayinde sermaye sahipliği açısından tasnif edilen kamu, özel ve yabancı sermayeli firmaların 1993-2014 yıllarındaki satış gelirleri toplamlarına göre her bir sermaye sahipliği türlerine ilişkin oluşturulan veriler Şekil 1 ve Şekil 2'de yer almaktadır.

2002 yılından sonra Tük imalat sanayinde yabancı sermayenin satış geliri payı, kamunun satış geliri payını aşarak Türk ekonomisinde ağırlığı giderek artmıştır. Ayrıca 2008 yılında başlayan küresel ekonomik kriz, Türk imalat sanayinde kamu ve yabancı sermayeden daha çok özel sermayenin satış gelirini olumsuz etkilemiştir.

Dışa açık iktisadi politikaların benimsenmesiyle Türk imalat sanayinde özel ve yabancı sermayeli firmaların hem sayıları hem de satış gelirleri giderek artmaktadır. Ayrıca liberal politika anlayışının ekonomide benimsenmesi ve 2004 yılından sonra özelleştirmeye hız verilmesi ile birlikte kamu sektörü birçok alanda geri çekilerek yerini özel sektöre bırakmıştır. Bu nedenle 1993-2004 ve 2004-2014 yılları arasındaki farklı sermaye sahipliği türlerinin satış gelirleri geçişkenliklerinin ne olduğu belirlenmeye çalışılmıştır. 
Şekil 1. Sermaye Sahipliği Türlerinin Toplam Satış Gelirleri (Milyar TL)

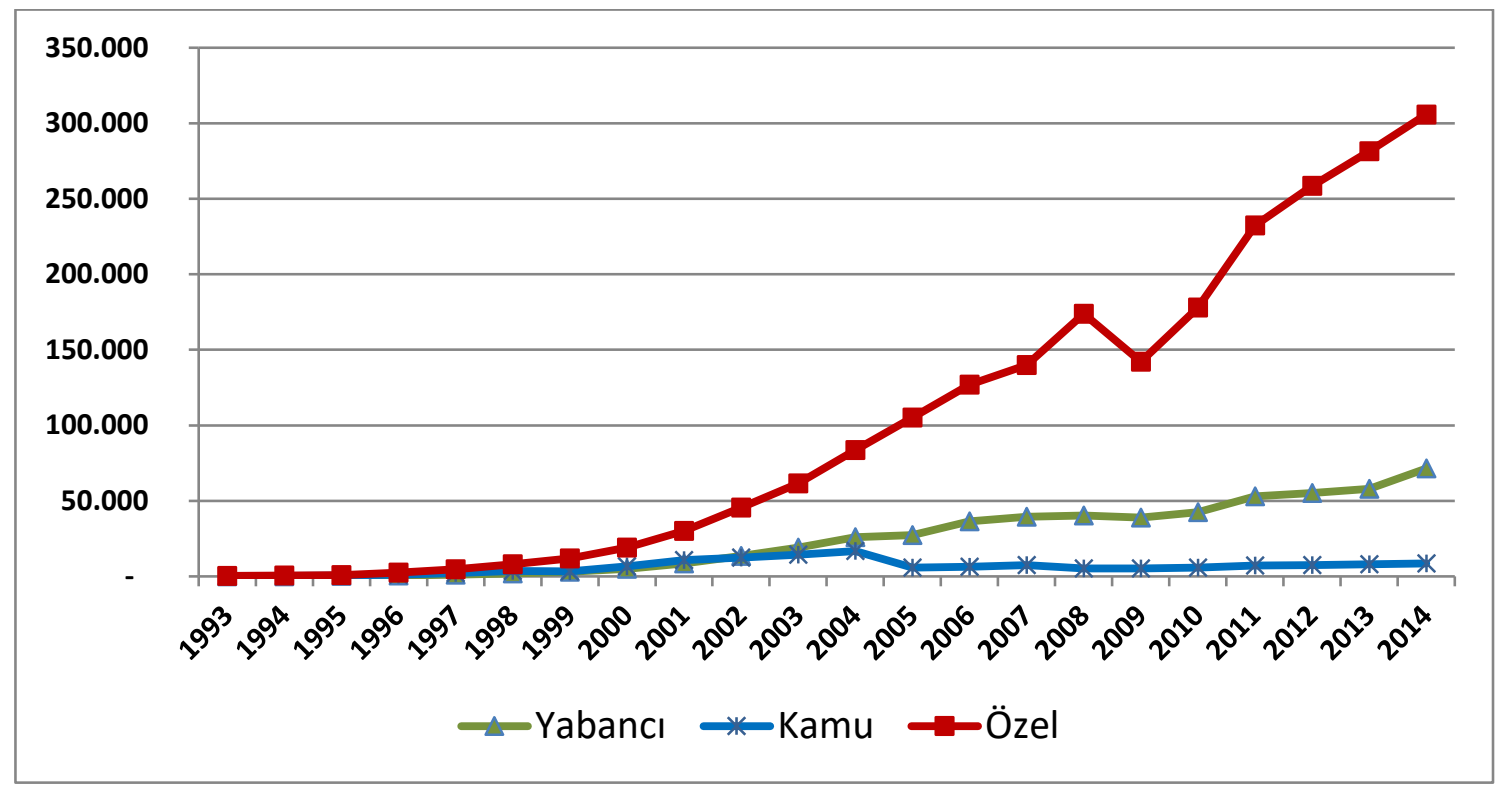

\section{Metodoloji}

\section{1. Íkinci Dereceden Programlama (Kuadratik) Modeline Dayalı Markov Yaklaşımı}

Türk imalat sanayinin gelecekteki satış gelirleri esasen geçmiş durumundan ziyade mevcut durumuna bağlıdır ve satış gelirlerinin yapısının dönüşümü homojen Markov özelliklerini sağlamaktadır. Bu nedenle, QPMarkov modeli olarak adlandırılan, ikinci dereceden programlama modeline dayanan yeni bir Markov yaklaşımı önerilmiştir. QP-Markov modelinin prosedürü şu şekildedir:

Adım 1: $\boldsymbol{x}_{\boldsymbol{i}}(\boldsymbol{t}) \quad(\mathrm{i}=1,2,3 ; \mathrm{t}=1,2, \ldots, \mathrm{T})$, farklı t dönemlerindeki i. sermaye sahipliği türünün (kamu, özel, yabancı) yıllık satış gelirlerinin toplanması

Adım 2: Her bir yıl için toplam satış gelirlerindeki i. Sermaye sahipliği türünün oranının hesaplanması

$$
w_{i}(t)=\frac{x_{i}(t)}{x(t)} \quad i=1,2,3
$$

Buna göre, yıllık satış gelirlerinin yapısal vektörü şu şekilde ifade edilir:

$$
w(t)=\left(w_{1}(t), w_{2}(t), w_{3}(t)\right)
$$

Adım 3: Farklı türde sektörler arasındaki geçiş olasılığı matrisini şu şekilde tanımlanır

$$
P=\left[\begin{array}{lll}
P_{11} & P_{12} & P_{13} \\
P_{21} & P_{22} & P_{23} \\
P_{31} & P_{32} & P_{33}
\end{array}\right]
$$

Burada $P_{i j}$, t-1 dönemindeki i. Sermaye sahipliğine ait olan oranın t döneminde j. Sermaye sahipliği türüne aktarıldığı tek aşamalı geçiş olasılığı olarak tanımlanır.

Adım 4: Kuadratik programlama ile Denklem (3)'deki tek aşama geçiş olasılığının hesaplanır. t-1 ve t dönemleri arasındaki geçiş ilişkisi şu şekilde ifade edilir: 


$$
\left(w_{1}(t-1), w_{2}(t-1), w_{3}(t-1)\right)\left[\begin{array}{lll}
P_{11} & P_{12} & P_{13} \\
P_{21} & P_{22} & P_{23} \\
P_{31} & P_{32} & P_{33}
\end{array}\right]=\left(w_{1}(t), w_{2}(t), w_{3}(t)\right)
$$

$\widehat{w}_{j}(t)$, farklı t dönemlerdeki j. sermaye sahipliği türünün simüle edilmiş satış gelirleri oranı olsun. Bu yüzden, oranlar $\widehat{w}_{j}(t)=\sum_{i=1}^{3} w_{i}(t) . P_{i j}$ denklemini sağlamalıdır. Gerçek $w_{i}(t)$ değeri ve simüle edilen $\widehat{w}_{j}(t)$ değeri arasındaki fark göz önüne alındığında, $\widehat{w}_{j}(t)=\sum_{i=1}^{3} w_{i}(t) \cdot P_{i j}+\varepsilon_{j}(t)$ denklemi elde edilir. $\sum_{t=2}^{T} \sum_{j=1}^{3} \varepsilon_{j}(t)$ biçimindeki toplam farkı minimize eden kuadratik programlama:

$$
\begin{aligned}
& \min \sum_{t} \sum_{j}\left(w_{j}(\mathrm{t})-\sum_{i=1}^{7} w_{i}(t-1) \cdot P_{i j}\right)^{2} \\
& \text { KIsıtlar: } \\
& \sum_{j=1}^{3} P_{i j}=1 \\
& P_{i j} \geq 0
\end{aligned}
$$

biçimindedir. Oluşturulan optimizasyon modeli çözüldüğünde, geçiş olasılık değerleri elde edilir. Buna göre, satış gelirlerinin gelecekteki oranları tahmin edilmektedir.

Bir sonraki adımda, Türk imalat sanayinin satış gelirinin tahmini ve öngörüsü için Gri Tahmin Modeli'nden yararlanılmaktadır. Böylece, geçiş yapısına göre ele alınan her sermaye sahipliği türünde öngörülen satış geliri oranları ile Türk imalat sanayinin toplam satış geliri projeksiyonu çarpılarak, her sektörün gelecekteki satış gelirlerinin elde edilmesi sağlanmaktadır.

\subsection{Gri Tahmin Modeli $M(1, N)$}

$X_{1}^{(0)}=\left\{x_{1}^{(0)}(1), x_{1}^{(0)}(2), \ldots, x_{1}^{(0)}(n)\right\} \quad$ in bir sistemin karakteristiklerinin veri dizisi ve $X_{i}^{(0)}=\left\{x_{i}^{(0)}(1), x_{i}^{(0)}(2), \ldots, x_{i}^{(0)}(n)\right\} \quad i=1,2, \ldots, N$ 'in ise ilgili faktörlerin dizileri olduğu varsayımı altında $X_{i}^{(1)}$ de $X_{i}^{(0)}, \quad i=1,2, \ldots, N$ 'in birinci derece birikimli üretim işlemi (the first-order accumulated generating operation, 1-AGO) olmak üzere,

$$
\frac{d X_{1}^{(1)}(t)}{d t}+a_{1} X_{1}^{(1)}(t)=b_{2} X_{2}^{(1)}(t)+b_{3} X_{3}^{(1)}(t)+\ldots+b_{N} X_{N}^{(1)}(t) \quad t=1,2, \ldots, n
$$

Bir GM $(1, N)$ gri diferansiyel denkleminin beyazlaştırma denklemi (whitenization equation) olarak tanımlanır.

Bağımlı değişken için $\frac{d X_{1}^{(1)}(t)}{d t}$ türevi

$$
\frac{d X_{1}^{(1)}(t)}{d t}=\lim _{h \rightarrow 0} \frac{X_{1}^{(1)}(t+h)-X_{1}^{(1)}(t)}{h}, \quad \forall t \geq 1
$$

biçiminde ifade edilir. 
Toplanan veriler bir zaman serisi veri olduğundan, $t$ ve $t+1$ arasındaki örnekleme zaman aralığı bir birim olarak kabul edilir. Ardından, $\frac{d X_{1}^{(1)}(t)}{d t}$ türevi, orijinal bağımlı zaman serisi verilerinin $X_{1}^{(0)}(t)$ ters birikmiş üretme işlemi (the inverse accumulated generating operation -IAGO) değişkenine Denklem (8)'deki gibi yaklaştırılabilir

$$
\frac{d X_{1}^{(1)}(t)}{d t} \approx \frac{X_{1}^{(1)}(t+1)-X_{1}^{(1)}(t)}{1}=X_{1}^{(0)}(t), \quad \forall t \geq 1
$$

Gri diferansiyel denkleminin çözümünden sonra, elde edilen parametre değerleri çözümün beyazlatma denklemine yerleştirilir. Böylece, gri diferansiyel denklemin çözümü,

$$
\hat{X}_{1}^{(1)}(t+1)=\left[x_{1}^{(1)}(0) \quad \frac{1}{\hat{a}_{1}} \sum_{k=2}^{N} \hat{b}_{k} X_{i}^{(1)}(t+1)\right] e^{\hat{a} t}+{\frac{1}{\hat{a}_{1}}}_{k=2}^{N} \hat{b}_{k} X_{i}^{(1)}(t+1), \quad \text { where } \quad x_{1}^{(1)}(0)=x_{1}^{(0)}(1)
$$

$N=1$ olduğunda, $\operatorname{GM}(1,1)$ çözümü şu şekilde yeniden yazılır:

$$
\hat{X}_{1}^{(1)}(t+1)=\left[x_{1}^{(1)}(0)-\frac{\hat{b}}{\hat{a}}\right] e^{-\hat{a} t}+\frac{\hat{b}}{\hat{a}}, \quad \text { where } \quad x_{1}^{(1)}(0)=x_{1}^{(0)}(1)
$$

Buna göre, GM $(1,1)$ esas olarak üstel tahmin modelinin bir türüdür.

Elde edilen parametre değerleri, çözümün beyazlaştırma (whitening) denklemine yerleştirildikten sonra $\hat{X}_{1}^{(0)}(t+1)=\hat{X}_{1}^{(1)}(t+1)-\hat{X}_{1}^{(1)}(t)$ ters birikmiş üretim operasyonundan $\hat{X}_{1}^{(0)}(t)$ tahmini sonuç elde edilir ve $\hat{X}_{1}^{(0)}(t)$ bir sonraki gözlemin tahmini sonucudur.

Orijinal gri modeli, katsayıları hesaplamak için en küçük kareler yöntemini kullanır. Ayrıca, bu yöntemin kullanılması, parametrelerin tahmin edilmesi için çok sayıda ve iyi bir dağılım verisi davranışı gerektirir.

Bununla birlikte, gri bir tahmin modeli sınırlı örneklem verisi (yaklaşık dört örnek veriler) kullandığında, bu tahminler önemli bir hata ile sonuçlanır. Özellikle bariz dalgalanmalara sahip veriler için, katsayıları hesaplamak için kullanılan en küçük kareler yöntemi hatırı sayılır bir hataya neden olacaktır (Hsu ve Wang, 2009). Bu nedenle, hem bahsedilen eksiklikleri gidermek hem de daha iyi bir performanslı tahmin sağlamak için global arama ve hızlı yakınsamalı genetik algoritma yaklaşımıyla çözülen geliştirilmiş gri tahmin modelleri $\operatorname{GAGM}(1, N)$, hem ilgili kusurları iyileştirmekte hem de daha iyi performanslı tahmin sağlamak için gri diferansiyel denklem katsayılarını tahmin etmede daha uygundur.

\subsection{Gri Tahmin Prosedürü- Genetik Algoritma Gri Tahmin Model- GAGM (1, N)}

Bu çalışmada $a_{1}$, geliştirme (development) katsayısı ve $b_{1}, b_{2}, \ldots, b_{N}$ gri girdi katsayılarının değerlerini bulmak için Genetik Algoritma (GA), GM $(1, N)$ modeli yöntemi benimsenmiştir. $G A$, çaprazlama, üreme ve mutasyon kullanır ve modelin her jenerasyon üzerindeki avantajını daha iyi bir hedef optimal çözüm üretmek için değerlendirir (Hsu ve Wang, 2009). Sorunun çözümünün performansı, optimizasyon probleminin amaç fonksiyonuna karşılık gelen bir uygunluk fonksiyonu ile değerlendirilir. Bu çalışmadaki fitness fonksiyonu, Ortalama Ortalama Mutlak Yüzde Hata (MAPE)'dir ve bu, örneklem ortalama hatasının minimumu olarak tanımlanmaktadır; 


$$
\min \quad M A P E=\frac{1}{N-1} \sum_{t=2}^{N}\left|\frac{X_{1}^{(0)}(t)-\hat{X}_{1}^{(0)}(t)}{X_{1}^{(0)}(t)}\right| \times 100
$$

Kısıtlar:

$$
\begin{aligned}
& \hat{X}_{1}^{(1)}(t+1)=\left[x_{1}^{(0)}(1)-\frac{1}{\hat{a}_{1}} \sum_{k=2}^{N} \hat{b}_{k} X_{i}^{(1)}(t+1)\right] e^{-\hat{a}_{1} t}+\frac{1}{\hat{a}_{1}} \sum_{k=2}^{N} \hat{b}_{k} X_{i}^{(1)}(t+1), \quad \forall t=1,2, \ldots, N-1 \\
& \hat{X}_{1}^{(0)}(t+1)=\hat{X}_{1}^{(1)}(t+1) \quad \hat{X}_{1}^{(1)}(t) \quad t=1,2, \ldots, N \quad 1
\end{aligned}
$$

\section{Bulgular ve Sonuçlar}

\subsection{Sermaye Sahipliği Türlerinin Satış Gelirleri Oranlarının Öngörüsü}

Çalışmanın bu bölümünde Türk imalat sanayinde faaliyet gösteren, sermaye sahipliği açısından farklı statüdeki firmaların sahip oldukları piyasa büyüklükleri ve dönüşümü, QP-Markov model olarak adlandırılan kuadratik programlama modeline dayalı yeni Markov yaklaşımı ile belirlenmiştir. Böylece, mevcut kararlar doğrultusunda Türk imalat sanayinde hangi sermaye sahipliği türlerinin ne oranda ön plana çıkacağı tespit edilmeye çalışılmıştır.

QP- Markov model prosedürüne göre, Adım 1'de Türk imalat sanayinde faaliyet gösteren farklı türdeki firmaların satış gelirleri verileri her bir sermaye sahipliği türünde TL cinsinden yıllık olarak toplanmıştır.

Adım 2'de sermaye sahipliği türlerinin satış gelirleri yıllık olarak hesaplanmıştır. (Bkz. denklem (1)).

Adım 3'te ise her bir sermaye türünün 1993-2004, 2004-2014 ve 1993-2014 yılları arasındaki farklı periyotlar için kuadratik optimizasyon denklemi (Bkz. Denklem (5)) çözülerek geçiş olasılık matrisleri oluşturulmuştur.

Elde edilen geçiş matrisine göre 1993-2014 dönemleri arasında Türkiye'nin en büyük 500 firmanın kamu, özel ve yabancı sermayeli türler arasındaki dönüşümlerinden ötürü sermaye sahipliği türlerinde satış gelirleri oranlarında birtakım geçişler olmuştur.

Şekil 3. Satış Geliri Oranlarının Geçişkenlikleri (1993-2004)

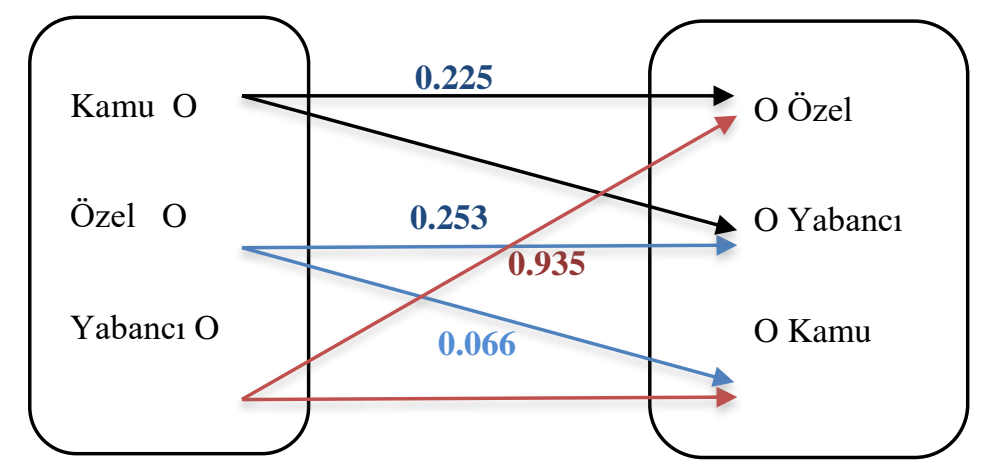

1993-2004 dönemleri arasında sermaye sahipliği türleri açısından satış gelirlerinin oranlarında kamu'dan özel'e $\% 22,5$, özel'den yabancı'ya $\% 25,3$, özel'den kamu'ya $\% 6,6$ ve yabancı'dan özel'e $\% 93,5$ düzeyinde geçiş olmuştur. Dolayısıyla satış geliri açısından en fazla geçiş özel sektöre olurken en az geçiş ise kamu sektörüne olmuştur. 
Şekil 4. Satış Geliri Oranlarının Geçişkenlikleri (2004-2014)

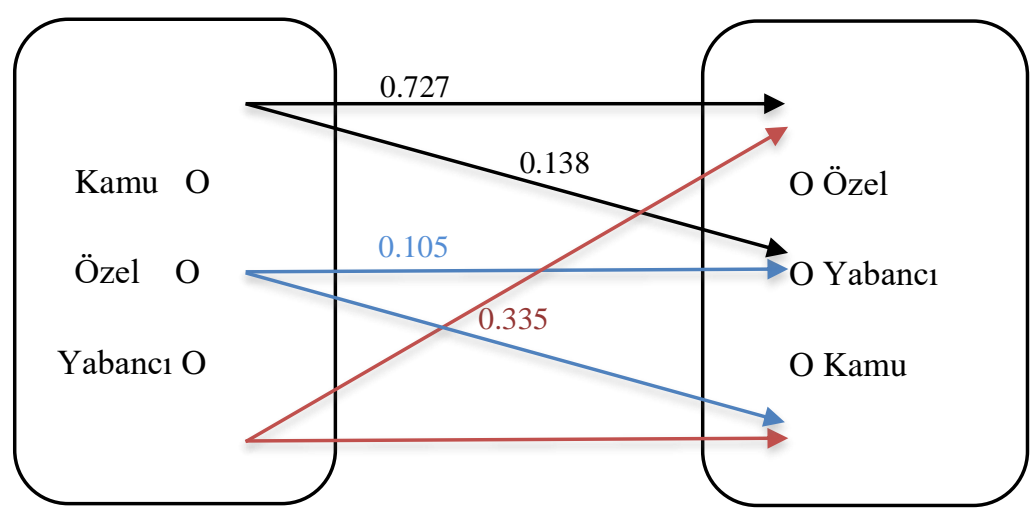

2004-2014 dönemleri arasında sermaye sahipliği türleri açısından satış gelirleri oranlarında kamu'dan özel'e \%72,7, kamu'dan yabancı'ya \%13,8, özel'den yabancı'ya \%10,5, yabancı'dan özel'e \%33,5 ve yabancı'dan kamu'ya ise \%54,3 düzeyinde geçiş olmuştur. Dolayısıyla 1993-2004 döneminde olduğu gibi satış geliri açısından en fazla geçiş özel sektöre olmuştur. Ancak 2004 yılında Türkiye'nin liberal ekonomik politikalar benimsemesi ve cumhuriyet döneminin en fazla özelleştirmenin yapılması nedeniyle geçiş oranlarında birtakım değişiklikler olmuştur. Buna göre, satış geliri oranlarında Kamu'dan özel'e geçiş artmıştır. 2004 öncesinde kamu'dan yabancı'ya satış geliri oranlarında hiç geçiş olmamışken özelleştirme ile birlikte kamu'dan yabancıya \%13,8 düzeylerinde geçiş olmuştur. 1993-2004 döneminde olduğu gibi 2004-2014 döneminde de özel sektör en fazla geçişin yapıldığı sektör olduğu tespit edilmiştir.

Şekil 5. Satış Geliri Oranlarının Geçişkenlikleri (1993-2014)



Bir bütün olarak incelendiğinde 1993-2014 dönemi satış geliri oranlarında kamu'ya hem özel'den hem de yabancı'dan bir geçiş olmamıştır. Satış geliri oranlarında en fazla geçiş özel sektöre olmuştur.

Markov karar zinciri modellemesine göre (denklem (5)) yapılan çözüm sonucunda sermaye sahipliği türlerinin satış gelirleri tahmini, gerçek değerleri ve mutlak hataları Tablo 3 'de elde edilmiştir. 
S. Kaynak - M. Eren

Tablo 1. 2004-2014 Dönemi Sermaye Sahipliği Türlerinin Satış Gelirleri Yapısının Tahmini, Gerçek Değerleri ve Mutlak Hataları ${ }^{1}$

\begin{tabular}{|c|c|c|c|c|c|c|c|c|c|c|c|c|}
\hline & & 2005 & 2006 & 2007 & 2008 & 2009 & 2010 & 2011 & 2012 & 2013 & 2014 & $A E(k)$ \\
\hline \multirow{3}{*}{$\begin{array}{l}\overrightarrow{\vec{\varepsilon}} \\
\stackrel{\overrightarrow{\widetilde{T}}}{ }\end{array}$} & Gerçek & 4.19 & 3.72 & 3.94 & 2.45 & 2.82 & 2.60 & 2.42 & 2.30 & 2.28 & 2.20 & \multirow{3}{*}{$\% 12$} \\
\hline & Tahmini & 4.28 & 2.96 & 3.11 & 3.11 & 2.56 & 2.93 & 2.64 & 2.54 & 2.41 & 2.34 & \\
\hline & Mutlak Hata & 0.02 & 0.20 & 0.21 & 0.27 & 0.09 & 0.13 & 0.09 & 0.10 & 0.05 & 0.06 & \\
\hline \multirow{3}{*}{ : } & Gerçek & 76.12 & 74.85 & 74.88 & 79.23 & 76.30 & 78.60 & 79.43 & 80.48 & 81.05 & 79.29 & \multirow{3}{*}{$\% 20$} \\
\hline & Tahmini & 75.78 & 77.77 & 76.87 & 76.98 & 78.83 & 77.33 & 78.53 & 78.93 & 79.47 & 79.79 & \\
\hline & Mutlak Hata & 0.00 & 0.04 & 0.03 & 0.03 & 0.03 & 0.02 & 0.01 & 0.02 & 0.02 & 0.01 & \\
\hline \multirow{4}{*}{$\begin{array}{l}\bar{\Xi} \\
\frac{\pi}{\pi} \\
\stackrel{0}{\pi} \\
\stackrel{\pi}{\nu}\end{array}$} & Gerçek & 19.69 & 21.43 & 21.18 & 18.32 & 20.88 & 18.80 & 18.15 & 17.22 & 16.66 & 18.52 & \multirow{3}{*}{$\% 6$} \\
\hline & Tahmini & 19.93 & 19.26 & 20.01 & 19.91 & 18.61 & 19.74 & 18.82 & 18.53 & 18.12 & 17.87 & \\
\hline & Mutlak Hata & 0.01 & 0.10 & 0.06 & 0.09 & 0.11 & 0.05 & 0.04 & 0.08 & 0.09 & 0.03 & \\
\hline & & & & & & & & & & & MAPE & $\% 6,97$ \\
\hline
\end{tabular}

Elde edilen tahmini bulgular ile orijinal veriler arasındaki sapmanın oransal ölçümü için yapılan hata analizi sonucunda ortalama mutlak sapma (Mean absolute percentage error-MAPE) değerleri 1993-2014 dönemi için \%10 bulunmuştur. 2004 ve 2014 dönemi için ortalama mutlak sapma ise \% 6,97 bulunmuştur. Bu bulgular (Lewis, 1982)'e göre son derece doğru bir tahmin olduğunun göstergesidir. Çünkü (Lewis, 1982), bir tahminin doğruluğunu değerlendirmek için uygun bir yol olarak MAPE sonuçlarını yorumlamıştır. Buna göre göre, MAPE değeri; $10 \%$ 'un altında ise son derece doğru tahmin, 10\%-20\% ise iyi bir tahmin, $20 \%-50 \%$ ise makul bir tahmin, 50\%'den büyükse yanlış bir tahmindir. Öyleyse bulguların geleceğe yönelik öngörüsünün de sağlıklı olabileceği sonucu çıkmaktadır.

Özelleştirmenin yoğun olarak yapıldığı 2004-2014 yıllarındaki geçiş matrisi doğrultusunda mevcut geçişlerin devam edeceği varsayılarak 2014 yılın sonrasındaki sermaye sahipliği türlerinin satış gelirleri oranları geleceğe yönelik Şekil 6'teki gibi tahmin edilmiştir.

Şekil 6. Sermaye Sahipliği Açısından Farklı Türlerin Satış Gelirleri Oranlarının Tahmini ve Öngörüsü

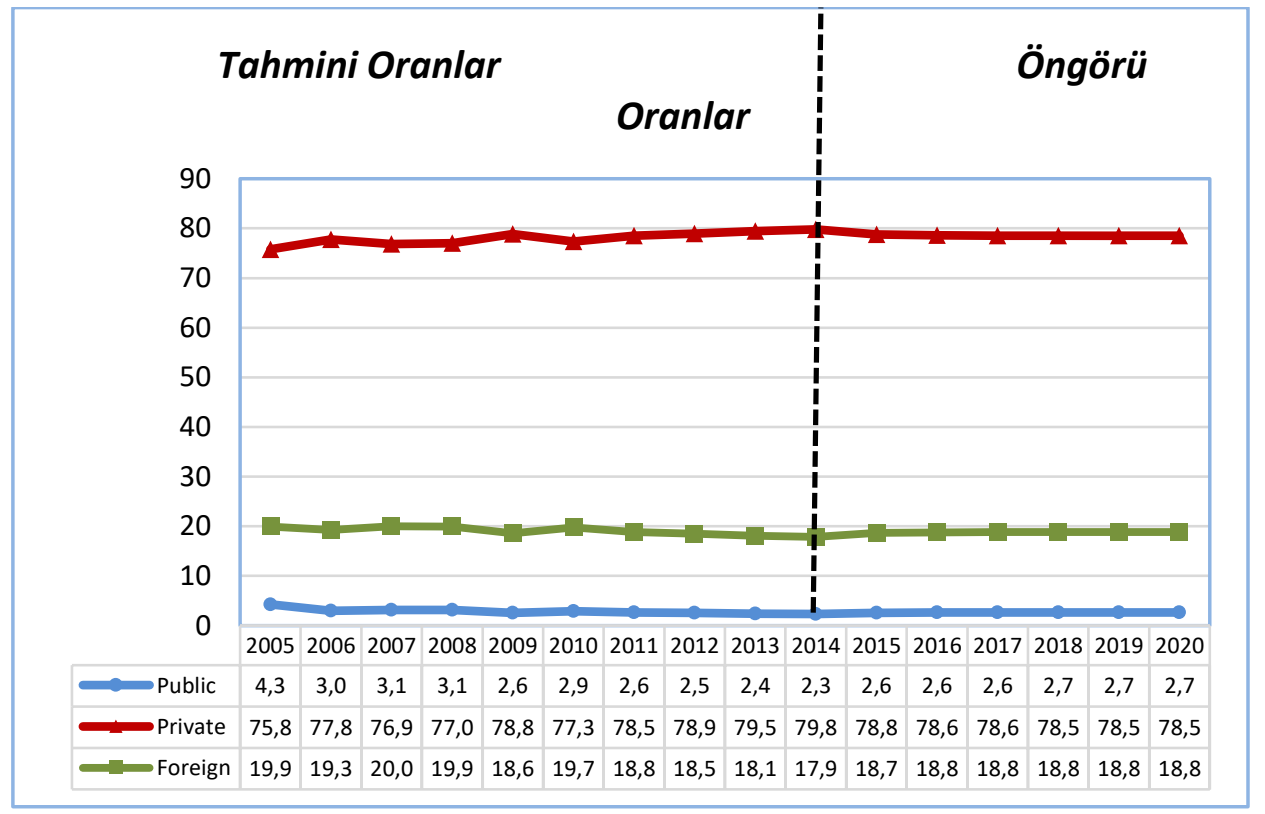




\subsection{Sermaye Sahipliği Türlerinin Toplam Satış Gelirlerinin GAGM(1,1) Prosedürü ile Tahmini}

Sermaye sahipliği türlerinin satış gelirlerine göre QP-Markov modeli vasıtasıyla sektörel geçiş yapısının oransal tahmini hesaplandıktan sonra, Simülasyon ve öngörüsü için Genetik Algoritma Gri Tahmin Modeli-GAGM $(1,1)$ prosedüründen yararlanılmıştır. Bölüm 3.3'te tanımlanan $\operatorname{GAGM}(1,1)$ modeli prosedürüne göre, toplam satış geliri toplamı için oluşturulan verilere göre kurulan modelin parametre değerleri Tablo 2'deki gibidir.

Tablo 2. GAGM(1,1) Modelinin Parametre Değerleri

\begin{tabular}{lcc}
\hline & \multicolumn{3}{c}{ Parametre Değerleri } \\
\cline { 2 - 3 } & b1 & b2 \\
\hline GAGM $(1,1)(\log ($ Satış Gelirleri $))$ & -0.005 & 25.488 \\
\hline
\end{tabular}

Sonuçlanan parametre değerlerine göre, simülasyon ve öngürü sonuçları aşağıdaki gibidir:

Tablo 3 . Satış Gelirlerinin Simülasyonu ve Öngörüsü

\begin{tabular}{|c|c|c|c|c|}
\hline & Yillar & $\begin{array}{l}\text { Satış Gelirlerinin } \\
\text { Gerçek Değeri }\end{array}$ & $\begin{array}{c}\text { Simülatif ve Öngörü } \\
\text { Değerleri }\end{array}$ & Mutlak Hata (\%) \\
\hline \multirow{10}{*}{ Simülasyon } & 2005 & 138.143 .044 .980 & 142.128 .867 .414 & 2.885 \\
\hline & 2006 & 169.649 .510 .114 & 161.650 .106 .508 & 4.715 \\
\hline & 2007 & 186.760 .061 .663 & 183.962 .910 .340 & 1.498 \\
\hline & 2008 & 219.511.983.524 & 209.523.135.041 & 4.550 \\
\hline & 2009 & 186.186.177.408 & 238.754 .102 .642 & 28.234 \\
\hline & 2010 & 226.471 .115 .390 & 272.280 .875 .238 & 20.228 \\
\hline & 2011 & 292.382 .047 .250 & 310.670 .903 .268 & 6.255 \\
\hline & 2012 & 321.303 .749 .090 & 354.757 .395 .555 & 10.412 \\
\hline & 2013 & 347.139 .775 .048 & 405.343.219.208 & 16.767 \\
\hline & 2014 & 385.681 .949 .172 & 463.466 .526 .334 & 20.168 \\
\hline MAPE (\%) & & & & 11.571 \\
\hline \multirow{6}{*}{ Öngörü } & 2015 & & 530.242 .348 .340 & \\
\hline & 2016 & & 607.063 .964 .170 & \\
\hline & 2017 & & 695.502.192.004 & \\
\hline & 2018 & & 797.382 .240 .590 & \\
\hline & 2019 & & 914.826 .255 .965 & \\
\hline & 2020 & & 1.050.198.174.596 & \\
\hline
\end{tabular}

MAPE değerinin \%11.57 çıkmıştır. Elde edilen bulgular 10\%-20\% arasında olduğu için oluşturulan GAGM(1,1) modelinin çıktıları (Lewis, 1982)'e göre iyi bir tahmin verir. 
Şekil 7. Satış Gelirlerinin Simülasyonu ve Öngörüsü

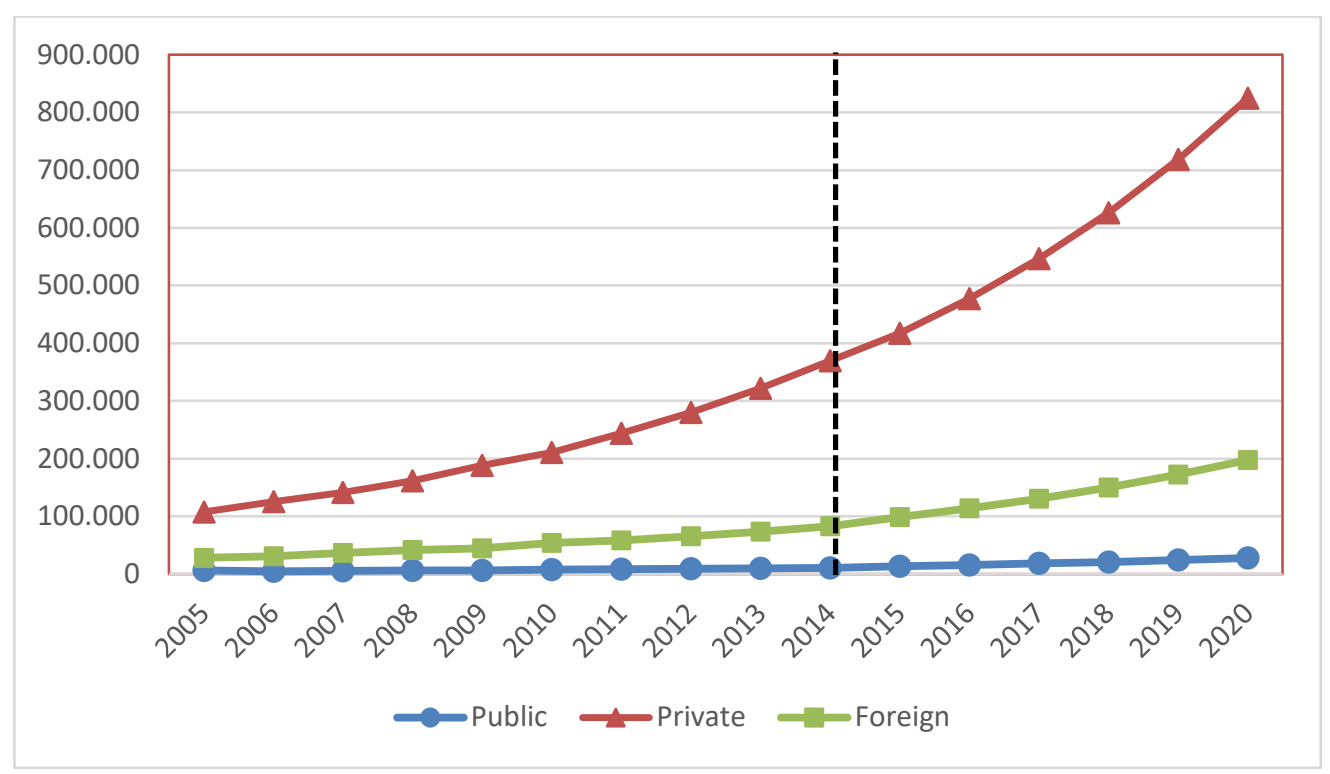

\section{Sonuçlar}

Türk imalat sektöründe faaliyet gösteren firmaların iktisadi verilerinin tahmini, firma yöneticileri ve iktisadi konularda karar vericiler için politikalarının oluşturulması ve etkin bir şekilde uygulanması için oldukça önemlidir. Ayrıca küresel ekonomik sorunlar ve bölgede devam eden siyasal belirsizlikler göz önüne alındığında firmaların satış geliri ve ihracat yapılarının analizi ve doğru tahmini yeni ekonomi politikalarının belirlenmesinde de önem arz etmektedir. Bu çalışmada Türk imalat sanayinde faaliyet gösteren kamu, özel ve yabancı sermayeli firmaların gelir ve ihracat miktarını tahmin etmek için gri tahmin modeli ile QP-Markov modeli kullanılmıştır. Hesaplama sonuçlarına göre, bu iki model ile satış gelir ve ihracat miktarı ve oranlarının tahmin edilebileceğini göstermiştir.

Özelleştirilmenin hız kazandığı 2004 yılından önce sonraki yıllara nispetten satış geliri açısından özel sermayeli firmalara geçişin daha düşük düzeyde gerçekleştiği tespit edilmiştir. Türkiye'de özelleştirme hız kazandıktan sonra yabancı sermayeli firmalara geçiş oranı daha çok ihracatta, özel sermayeli firmalara ise daha çok satış geliri açısından geçiş gerçekleşmiştir. Dolayısıyla Türk imalat sanayinde toplam ihracat açısından yabancı sermayenin büyüme hızı artarken, satış geliri açısından ise özel sermayeli firmaların büyüme hızı düşecektir. Kamu sermayeli firmalar ise hem ihracat hem de satış geliri açasından büyüme hızı düşecektir.

\section{Son Notlar}

1. Her bir yılın mutlak hatası, $A E(k)=\frac{1}{3} \sum_{t=2004}^{2014}\left|\frac{\operatorname{Gerçek}(k)-T a h m i n i(k)}{\operatorname{Gerçek}(k)}\right|, k=K a m u$, Özel ve Yabancı sermaye sahipliği türünün satış geliri ve ihracat oranları Ortalama mutlak hata, $M A P E=\frac{1}{10} \sum_{k=1}^{10} A E(k)$

\section{Kaynaklar}

Albeni, M. (2005). Kamu ve özel sektör imalat sanayinde teknolojik öğrenme performansına ilişkin bir karşılaştırma. Yönetim Bilimleri Dergisi, 3(1), 127-140.

Berköz, L. (2005). Locational determinants of foreign investors in istanbul. Journal of Urban Planning and DevelopmentASCE, 131, 3, 140-147. 
Berköz, L., \& Türk, Ş. Ş. (2007). Yabancı yatırımların yerseçimini etkileyen faktörler: Türkiye örneği. iTüDERGisi/a, 6(2), 59-72.

Casale, G., Sansottera, A., \& Cremonesi, P. (2016). Compact Markov-modulated models for multiclass trace fitting. European Journal of Operational Research, 255(3), 822-833.

Jenkins, R. (1987). Transnational corparation and unevan developmant: Internationalization of capital the third world. New York: Mehteuen.

Hsu, L-C., \& Wang, C-H. (2009). Forecasting integrated circuit output using multivariate grey model and grey relational analysis. Expert Systems with Applications, 36(2), 1403-1409.

Julong, D. (1983). Grey fuzzy forecast and control for grain. J. Huazhong Univ. Sci. Technol. Med. Sci, 2, 1-8.

Julong, D. (1985). Grey control system. Printing House of Central China University of Science and Technology, Hubei.

Krueger, A. O., \& Tuncer, B. (1982). Growth of factor productivity in Turkish manufacturing industries. Journal of Development Economics, 11(3), 307-325.

Lewis, C.D. (1982). Industrial and business forecasting methods: A practical guide to exponential smoothing and curve fitting. Butterworth-Heinemann.

Liisberg, J., Moller, J. K., Bloem, H., Cipriano, J., Mor, G., \& Madsen, H. (2016). Hidden Markov Models for indirect classification of occupant behaviour. Sustainable Cities and Society, 27, 83-98.

OECD, (2015). G20/OECD Principles of Corporate Governance.

https://www.oecd-ilibrary.org/governance/g20-oecd-principles-of-corporate-governance_9789264257443-tr (Erişim Tarihi: 16.11.2017)

ÖiK (2014). İmalat sanayinde dönüşüm. Özel İhtisas Komisyonu Raporu, Kalkınma Bakanlığı, Ankara.

TCMB Sektör Raporları, (2017). http://www.tcmb.gov.tr/wps/wcm/connect/TCMB+TR/TCMB+TR/Main+Menu/ Istatistikler (Erişim Tarihi: 25.02.2018).

Türedi, S., \& Terzi, H. (2009). Türkiye'de kamu-özel imalat sanayinde ücret ve işgücü verimliliği ilişkisi. Eskişehir Osmangazi Üniversitesi Sosyal Bilimler Dergisi, 10(1), 144-162.

Ren, F., \& Gu, L. (2016). Study on transition of primary energy structure and carbon emission reduction targets in China based on Markov Chain Model and GM (1,1). Mathematical Problems in Engineering, 2016, 1-8.

Shen, Z-L., Huang, T-Z., Carpentieri, B., \& Wen, C. (2015). A cost-effective smoothed multigrid with modified neighborhood-based aggregation for Markov chains. Mathematical Problems in Engineering, 2015.

Wang, J., Jiang, H., Zhou, Q., Wu, .J, \& Qin, S. (2016). China's natural gas production and consumption analysis based on the multicycle Hubbert model and rolling Grey model. Renewable and Sustainable Energy Reviews, 53, 11491167.

Wu, L., Liu, S., Liu, D., Fang, Z., \& Xu, H. (2015). Modelling and forecasting CO2 emissions in the BRICS (Brazil, Russia, India, China, and South Africa) countries using a novel multi-variable grey model. Energy, 79, 489-495.

Xie, N-m., Yuan, C-q., \& Yang, Y-j. (2015). Forecasting China's energy demand and self-sufficiency rate by grey forecasting model and Markov model. International Journal of Electrical Power \& Energy Systems, 66, 1-8. doi: https://doi.org/10.1016/j.ijepes.2014.10.028

Zaim, O., \& Taskin, F. (1997). The comparative performance of the public enterprise sector in Turkey: A Malmquist productivity index approach. Journal of Comparative Economics, 25(2), 129-157.

Zhao, N-b., Yang, J-I., Li, S-y., \& Sun, Y-w. (2014). A GM (1,1) Markov chain-based aeroengine performance degradation forecast approach using exhaust gas temperature. Mathematical Problems in Engineering, 1-11.

http://www.tuik.gov.tr/PreHaberBultenleri.do?id=24826(Erişim Tarihi:14.11.2017). 